\title{
Addressing Complex Challenges through Adaptive Leadership: A Promising Approach to Collaborative Problem Solving
}

\author{
Tenneisha Nelson \\ Doctoral Candidate \\ University of Saskatchewan \\ tenneisha.nelson@usask.ca \\ Vicki Squires \\ Assistant Professor \\ University of Saskatchewan \\ vicki.squires@usask.ca
}

\begin{abstract}
Organizations are faced with solving increasingly complex problems. Addressing these issues requires effective leadership that can facilitate a collaborative problem solving approach where multiple perspectives are leveraged. In this conceptual paper, we critique the effectiveness of earlier leadership models in tackling complex organizational issues. We then examine one promising model, adaptive leadership, in detail and propose that this model provides a leadership approach for addressing current organizational realities. The model, proposed and developed over the last two decades, fundamentally supports the assumption of leadership by multiple stakeholders, with the formulation of the leadership dependent on the emergent problem. Adaptive leadership, with its focus on collaborative problem-solving utilizing multiple perspectives, is especially applicable to large organizations faced with solving complex problems involving many stakeholders.
\end{abstract}

\section{Introduction}

Leadership plays a vital role in facilitating the development of effective and innovative schools and educational systems that promote quality teaching and learning (Dinham, 2005; Leithwood, 2007). The environment within which educational leaders operate is dynamic and continues to change in response to external pressures and societal changes. This dynamic environment manifests itself in an ever increasing demand from stakeholders for improved performance in the operations of educational institutions. Robertson and Webber (2002) stated that "educational leaders today are compelled to practice in complex politicized diverse conditions to a greater degree than ever in the history of education" (p. 520). Given these conditions, Ingleton (2013) argued that leaders needed to be even more creative and innovative. Leadership in education then plays a key role in navigating the ever changing environment. When describing school leadership, for example, Kelly and Peterson (2002) pointed out that "in educational administration the range of problems that present themselves is also large, but procedures for solving them tend to be less routinized and unique problems present themselves much more frequently" (p. 364). Owens and Valesky (2007) posited that there is a growing body of literature which addresses the need to find new and better ways to lead under these unstable and unpredictable conditions. In offering a solution to this quandary, Heifetz and Linsky (2004) 
proffered that, given this complex environment, educators need to embrace the practice of adaptive leadership.

In this conceptual paper, we seek to present a compelling case for the infusion of adaptive leadership practices within all levels of educational systems. We first examine several of the well-known leadership theories, including the limitations of these theories, and then pay particular attention to adjectival and situational theories in an effort to contextualize adaptive leadership practices as a means of responding to the challenges being faced in today's educational environment. We then describe the model in more detail and illustrate its potential impact in educational settings. Finally, we identify implications that the application of this type of leadership may have on educational institutions, including primary, secondary, and tertiary education.

Understanding leadership. The concept of leadership continues to be a central focus of study in academic fields. For example, Heifetz, Kania, and Kramer (2004) suggested that leadership is "the activity of mobilizing people to tackle the toughest problems and do the adaptive work necessary to achieve progress" (p. 24). On the other hand, Gardner (1990) defined leadership as "the process of persuasion or example by which an individual (or leadership team) induces a group to pursue objectives held by the leader or shared by the leader and his or her followers" (p. 17), and furthermore, indicated that leaders are situated within a particular historic context, a particular setting, and a particular system. Gardner (1990) pointed out that leaders are essential to the organization and perform activities that are integral for the group to accomplish its purposes. Given its importance to organizational effectiveness, Leithwood (2007) suggested that leadership significantly impacts the quality of the school organization and student learning. He further contended that talented leadership in schools is connected with improvements in student achievement. Given the importance of leadership in organizations, it is not surprising that there have been numerous theories advanced, especially within the last few decades.

The Evolution of Leadership Theories and Practices. The area of leadership research continues to evolve, as studies unearth more about the concept and as social and political contexts change. Leadership theories, generally, and more specifically their applications in the field of education have undergone a significant shift over time. According to Leithwood, Jantzi, and Steinbach (1999), "there is much yet to be learned about leadership, the different forms it can take and the effects of these forms" (p. 6). The following section examines several leadership theories that have been advanced in the literature on educational administration.

Leadership research has traditionally focused on one aspect of leadership or variables that influence leadership (Chance, 2009). Some theories focus on the agency of the leader and his or her role in transforming the organization. Other theories examine the environment and the systems that enable leadership. These descriptions of leadership are highly contextual, being linked to the industrial and post-industrial time period in which they were advanced and thus, are somewhat outdated given the current climate within which educational organizations operate. These theories include trait theories, behavioural theories, as well as situational theories of leadership. 
Trait based theories of leadership. With the aim of finding out what makes certain individuals great leaders, this approach to the study of leadership is influenced by the Great Man Theory, which implies that "leadership is reserved for only the gifted few" (Northouse, 2013, p. 47). Premised on the assumption that traits can predict the likelihood of an individual attaining a leadership position and being effective in the role, attention is paid to traits such as abilities, physical and personality characteristics and how they differ between leaders and non-leaders. In his review of 124 trait studies undertaken between 1904 and 1947, Stogdill (1948) sought to compile a comprehensive list of universal traits related to successful leadership. The results of this review outlined several leadership traits that distinguished a leader from a non-leader in a group; among these traits are initiative, persistence, self-confidence, knowing how to get things done, adaptability and sociability. While initial research seemed to suggest a range of inheritable traits, later work by researchers such as Zacarro (2007) purported that a range of individual characteristics supported effective leadership and combinations of these traits and attributes needed to be considered within the situation itself. However, continuing critiques of trait based leadership theories include the lack of a definitive identification of which traits contribute to leadership effectiveness and leadership outcomes,

Behavior based theories of leadership. This approach to leadership investigates behaviours enacted by leaders and how these behaviours are reflected in the treatment of followers (Day \& Antonakis, 2012). Douglas McGregor (1960), in studying behaviours of leaders in relation to their followers, distinguished between two types of leaders. The distinguishing characteristic between the types is their beliefs and assumptions regarding how people approach work. The behaviour of Theory $\mathrm{X}$ leaders reflect their view that the average individual dislikes work and therefore needs to be coerced and controlled for them to work effectively (McGregor, 1960). According to McGregor, the Theory Y leader, on the other hand, sees workers as motivated and happy to work. Therefore this leader will be more participatory in their approach to leadership; their participation, though, presupposes that workers would be allowed to actively participate in organizational decision making. Further work by theorists such as Blake and Mouton (1985) noted the two types of behaviours of leaders: task and relationship. Leaders need to focus their efforts on both areas in order to be the most effective. Continuing critiques of this group of theories include the lack of research that clearly links the types of task and relationship behaviours to positive leadership outcomes, and lack of identification of a style of leadership that is effective across all situations.

Skills theories of leadership. Katz (1955) first identified three broad categories of skills that leaders should exhibit: those aligned with technical skills, human skills, and conceptual skills. Further work by theorists such as Mumford, Zaccaro, Harding, Jacobs, and Fleishman (2000) identified five components of leadership skills: competencies, individual attributes, leadership outcomes, career experiences, and environmental influences. Furthermore, the components of their 
skills model was further categorized into discrete abilities and skills. Because this model was developed based on military organizations (Mumford, et al., 2000), criticisms of this model include the lack of research and application to other organizations. Additionally, several of the components are reliant on traits, such as cognitive ability, and the theory does not provide insight into leadership development and the translation of some of these skills into leader effectiveness.

Situational theories of leadership. A recognized limitation of theories focusing on skills, traits, and behaviours is the influence of context on leadership. Hersey and Blanchard (1969) and subsequently over the following decades, Blanchard and his associates developed a situational leadership model. Within this model, the directive and supportive elements of strong leadership are described, but there is a recognition that these elements need to be examined within the particular context or situation (Blanchard, Zigarmi, \& Zigarmi, 2013). Moreover, Blanchard and his associates developed a series of questionnaires to measure situational leadership. This very prescriptive approach has been critiqued because of the lack of theoretical underpinnings of the approach, the lack of research regarding application, and the lack of examination of the dynamics between approaches to leadership and the followers' development level (Northouse, 2013).

Transformational and transactional leadership. As research on leadership developed, other theories emerged as scholars sought to examine the effectiveness of leadership by looking at the ways in which leadership can transform organizations (Chance, 2009). Burns (1978), in his seminal work, focused on two types of leader-follower relationships, namely transactional and transformational leadership. The transactional leader influences followers through the "exchange of valued things" (Burns, 1978, p. 20). On the other hand, a transformational leader encourages "an engagement between leaders and followers bound by a common purpose where leaders and followers raise one another to higher levels of motivation and morality" (p. 20). In comparing the two styles, the transformational leader is considered the ideal state of leadership. However, the theory has been criticized for its focus on traits, and the role traits such as charisma play on elements such as followership; reliance on traits rather than behaviours suggests that leadership cannot be learned, Further criticism can be levied around the underlying idea of the heroic leader who inspires other to follow an inspirational vision, and enact change in the organization.

Distributed leadership. A more recent model of leadership that has been advanced is that of distributed leadership. This theory of leadership does not focus on one person as the leader but instead pays attention to the interactions between persons within the organization in an effort to understand leadership. Spillane (2005) outlined that distributed leadership involves interactions of school leaders, followers and their situations, the "interactions among the various leaders in a given situation define leadership practice as individuals play off one another" (p. 144). There may be positional leadership, but leadership roles are distributed among key stakeholders within the organization. This approach ensures multiple perspectives and leadership styles are incorporated into a working body that has defined roles. A critique of this approach, though, is that it appears to be a way to distribute the work of leadership across the formal and informal leaders of the institution without focusing at the underlying complex issues of the organization. While distributed leadership may engage more members in the organization, and 
build investment in the advancing of the organizational goals, the model does not focus on the collaborative efforts required for difficult problem-solving.

Inadequacies of Previous Theories. The different leadership theories all play a role in understanding school leadership. The trait and behaviour theories provide only a list of characteristics and behaviours that individuals should possess that may contribute to effective leadership (Chance, 2009), but yet research has yet to uncover an optimal combination for leadership that works effectively in all situations. Examining leadership solely based on traits and behaviours is inadequate since the context within which leaders operate also play an integral role in determining their effectiveness. Moreover, the debate regarding whether leadership is innate or learned is a not a helpful approach to resolving issues of leadership in organizations.

It should be noted that leadership studies that have paid exclusive attention to the actions of the individual leader or administrator and their role in improving the organization tended to attribute the improvements made to the person charged with leading the institution. According to Evers and Lakomski (2013), one of the draw backs of individualism "is that the emphasis on the leader as an individual can both bracket and discount the causal field in which organizational functioning occurs" (p. 164). Spillane (2015) also rejected leader-centric studies in education, suggesting that leadership based on the individual is flawed. Spillane (2015) further argued that individual focused research tends to pay attention to the logistics of leadership rather than the enactment of leadership. Paying attention to not only what individuals do but how they interact within their socio-material environment as they lead (the practice of leadership) should be the focus of any study in leadership. Speaking from his years of studies in political leadership, Cronin (1984) emphasized that leadership is "highly situational and contextual... there is chemistry between leaders and followers which is usually context specific" (p. 23). Ultimately, it is in this context that leadership can be understood, as emphasized by Spillane (2005) who proposed that an examination of leadership practices is key to understanding school leadership.

Attempting to confine leadership to one "key thing" is an activity in futility because there appears to be no one right model that works across all cultures and contexts (Riley \& Macbeath, 2002). Gardner (1990) stated that "the issues are too technical and the pace of change too swift to expect that a leader, no matter how gifted will be able to solve personally the major problems facing the system over which he or she presides" (p. 26). Whether it is internationalization pressures, global mobility, economic disparity, competitive recruitment of students, or the pace of technological change, educational leaders need to work together with others in the organization to address the challenges.

In examining school leadership within several contexts Riley and Macbeath (2002) advanced that "leadership can be developed, nurtured and challenged; (it is) not static, leaders do not learn how to do school leadership and then stick to set patterns and ways of doing things" (p. 356). In other words the concept of leadership is evolving as society changes. With this in mind, Heifetz et al. (2004) advanced that leadership is better understood by focusing on what is done instead of focusing on individual attributes. In defining leadership they contended that leadership is the "activity of mobilizing people to tackle the toughest problems and do the adaptive work necessary to achieve progress" (Heifetz, et al., 2004, p. 24). Solving complex 
current problems requires a leadership style that influences the organization in a way that galvanizes a collaborative response to the problem.

Adaptive leadership. The challenges that educational organizations face today have far reaching implications for the sustainability of the institutions and its members. Challenges include issues such as the best way to implement reform for the mutual benefit of all stakeholders or to overcome deep rooted systemic problems that curtail the successful operation of the organizations. Although Heifetz and his colleagues originally developed the model of adaptive leadership within the context of business, they identified that their model could be applied to educational systems because the problems are complex and multi-faceted. They contended that this model was process and follower oriented that proposed a prescriptive approach to resolving these challenges. In this context Heifetz and Linsky (2007) purported that:

Leadership in education means mobilizing schools, families, and communities to deal with some difficult issues - issues that people often prefer to sweep under the rug. The challenges of student achievement, health, and civic development generate real but thorny opportunities for each of us to demonstrate leadership every day in our roles as parents, teachers, administrators, or citizens in the community. (p. 7)

Owens and Valesky (2009) pointed out that the degree of change or stability in the environment should influence the selection of a strategy for leadership. Principals are problem solvers, who are expected and needed to address and buffer the technical care of the organization the school from the immediate and pressing demands of student's parents and other short term sources of perturbation in the system (Kelly \& Peterson, 2002). Indeed, in taking on this role as problem solvers, Kelly and Peterson (2002) further pointed out that principals are also expected to "work effectively in increasing diverse fragmented and pluralistic communities with vocal stakeholders," all the while fulfilling their central role of facilitating school reform and improvement (p. 351). With this in mind, leaders are now more than ever required to reframe how leadership is understood and enacted.

Robertson and Webber (2002) called for educational leaders to "move past the practices that were successful in an industrial model of education to address the ambiguity and complexity of working in a rapidly changing, diverse society" (p. 520). There is a need, as outlined by Kelly and Peterson (2002), for principals to have both problem finding and problem solving skills in order to address not only routine challenges, but also unique emergent issues. Bringing attention to the preparation programs for principals, Kelly and Peterson (2002) highlighted the need for these programmes "to address the existing realities — by providing skills, knowledge and experiences that will prepare future principals" (p. 359). In an environment where there are no clear cut solutions for many of the challenges being faced, school leaders need to engage in adaptive leadership techniques. Although researchers of adaptive leadership contend that this approach is applicable to all large organizations, there has been little written on this model within post-secondary education. However, senior administration in universities and colleges are facing many emergent issues as well, including a move away from public funding of post-secondary education to a model of more diversified funding (Austin \& Jones, 2016). Indeed, the term of post-secondary presidents are becoming shorter and shorter as the multidimensional tensions on campuses grow (Paul, 2015; Trachtenberg, Kauver, \& Bogue, 2013). 
Application of Adaptive Leadership in Educational Institutions. Given the complex environment of educational institutions, a more robust model of leadership would be a useful tool to assist leaders of these organizations to navigate this dynamic landscape. Owens and Valesky (2007) have advanced that the "problems facing schools today are adaptive problems... and require adaptive leadership concepts and techniques" (p. 271). In referring to the landscape of post-secondary education Randall and Coakley (2007) indicated that an "outcome of the changing academic environment is the need to challenge models of leadership that focus on the competencies, behaviors, and situational contingencies of individual leaders" (p. 325). Leadership, when seen in this light, requires a learning strategy, a new approach to leadership; "the adaptive demands of our time require leaders who take responsibility without waiting for revelation or request. One can lead with no more than a question in hand" (Heifetz \& Laurie, 2011, p. 78). Leaders and organizations need to adapt to the evolving societal and political contexts.

Heifetz (1994) advanced a model of leadership that can equip principals or postsecondary leaders to navigate the challenges common to uncertain educational environments. This model views the problems that school leaders possibly face as either technical or adaptive. According to Owens and Valesky (2007), technical problems are clear and can be solved by applying technical expertise, while adaptive problems are "complex and involve so many ill understood factors that the outcomes of any course of action is unpredictable" (p. 271). A technical challenge is not necessarily quickly resolved; however, the problem is readily understood and the solution is achievable using current policies and practices. On the other hand, an adaptive challenge requires careful examination or diagnosis of the problem itself, followed by actions that may include changes to people's assumptions, attitudes, and behaviours. A further complication in the diagnosis of the issue may be that the challenge is both technical and adaptive; parts of the solution can be achieved using current practices and resources, whereas other elements of the issue require much more complex approaches.

Heifetz, Grashow, and Linsky (2009) emphasized that diagnosing the problem was a critical step that required considerable time for a thorough evaluation. They cautioned leaders to put aside the pressures to react too quickly to the problem. Proper diagnosis requires a diagnosis of the system, of the problem, and of the political landscape. After this careful and systematic collection of data and related information, the next task is the interpretation of the data (Heifetz et al., 2009). This stage is essential for identifying the technical and adaptive elements of the challenge which then informs decisions with regard to courses of action. The leaders should design interventions that address these challenges adequately with consideration given to the context and available resources. Heifetz et al. (2009) noted that this process involves potential conflict, as the organization moves into a "productive zone of disequilibrium" (Heifetz et al., 2009 , p. 30). The solutions are unlikely linear, and introduce times where members need to confront their ideas, beliefs, and behaviours. Leaders of change need to understand that resistance and conflict are an expected part of the process (Heifetz et al., 2009).

In shedding light on adaptive leadership in practice, Heifetz, et al. (2004) shared the experience of three foundations in Pittsburg, United States that faced an adaptive problem. The foundations abruptly suspended their funding to local public schools sending the system into a quandary. This move forced the school board to pay attention to a concern the foundations had repeatedly brought up, which is the manner in which the school district operated. As a result of 
this bold move, a Mayoral Commission was launched to conduct an independent assessment of the city's school system. This assessment led to dramatic reforms in the way the school district was governed and operated. According to Heifetz, et al. (2004) many of the problems the district encountered could be traced back to a school board "long paralyzed by intramural conflicts" ( $p$. 22). Using this incident as a case, Heifetz, et al. (2004) advanced that in dealing with adaptive problems getting people to pay attention to a certain issue is the first hurdle. As they explained, this focus was successfully done when the foundations publicly announced the withdrawal of their support of the public schools valued at approximately 12 million dollars.

As illustrated in this example, the second step in the adaptive process involves the generation and maintenance of productive distress. Heifetz, et al. (2004) pointed out that "adaptive problems often take a great deal of time to resolve, with progress coming in fits and starts. The erratic pace often distresses stakeholders" (p. 30). They further added that "the job of adaptive leadership is not to eliminate this stress - and thus reduce the impetus for adaptive solutions - but to harness it, keeping it at a level that motivates change without overwhelming participants" (Heifetz, et al., 2004, p. 30). Fostering an adaptive culture includes managing this conflict and making the process an acceptable part of the organization's practices.

Framing the issues is the next step in the process, where participants are made aware that difficult problems present opportunities as well as challenges. Mediating the conflict among stakeholders is the final component of the process. According to Heifetz, et al. (2004), "many different people and groups may hold keys to the solutions of complex adaptive problems. But trying to get them all moving in the same direction may result in conflict across racial, cultural, or socioeconomic lines" (p. 30). The members are tasked with mitigating these potential challenges by understanding the necessity of collaborative problem solving even when it is difficult.

It should be noted that "tackling complex adaptive social problems is not easy" (Heifetz, et al, 2004, p. 30), a disclaimer made by the authors. However, given its potential to assist in providing tangible and sustainable responses to the challenges that are evident in an everchanging educational landscape makes it viable as a leadership process worthy of investigation and application in challenging leadership situations. Engaging in this form of leadership requires a shift from the traditional view of leadership as an "authoritative experience" (Heifetz \& Laurie, 2011, p. 58) where leaders are the sole source of authority for solving organizational problems. Arguably, solutions to adaptive problems in schools are not found in the leaders "but in the collective intelligence of employees at all levels, who need to use one another as resources, often across boundaries, and learn their way to those solutions" (Heifetz \& Lauire, 2011, p. 58).

The adaptive leadership framework provides a useful means for principals and postsecondary senior administration to navigate the uncertain climate in which schools have to operate. Similar to continuous improvement initiatives in the manufacturing sector where multidisciplinary teams are used to solve unique organizational problems in an effort to move the organization to the next level, this approach can also assist educational leaders to overcome adaptive challenges that threaten their existence. One of the first things this method of intervention emphasized is that leaders do not have all the answers to the problems an organization faces. In adaptive leadership, workable solutions are usually found by engaging 
those persons who are closest to the problem within the system; they work with the system every day and know what can or cannot work for its improvement. This approach implies that all individuals are treated equally in diagnosing the problem and finding workable solutions. They are thereby given a voice in the organization, and actively participate to ensure its viability. In such a situation the leader's role is to facilitate the emergence of these solutions, and put processes and systems in place to facilitate their implementation.

While the structure of post-secondary organizations are significantly different from the other educational systems, this type of leadership can also be utilized. Diagnosing the complex system is the first piece of the puzzle; understanding the political landscape is even more challenging with the collegium model of governance and decision making (Austin \& Jones, 2016). However, the work of identifying and understanding adaptive challenges is still very relevant. In some cases, solutions could include recrafting of policies and processes which would entail the commitment of necessary stakeholders to make relatively small adjustment to address technical challenges. In other cases, the issues will require interdisciplinary problem solving to generate innovative solutions, such as improving post-secondary outcomes for Indigenous students. Universities and colleges are engaging in interdisciplinary research into global challenges such as food and water security. This collaborative work in research, though, is not extended towards collaborative models of decision making and governance. Rather, universities especially have a reputation for holding onto traditional models and structures (Austin \& Jones, 2016). The individualistic and competitive nature of distributing resources across the campus becomes a significant barrier to implementing adaptive leadership more broadly across the campus. Although collegial processes promote multiple levels of input in decision making, those same processes encode a very structured method of addressing change (Austin \& Jones, 2016).

Implications for Practice and Research. The model of adaptive leadership was developed as a very practical approach. Because of this genesis, the process includes helpful strategies for addressing challenges. For example, Heifetz et al. (2009) noted the need for engaging in occasional views from the 'balcony' where leaders take a step away and examine the broader view of the organization. Furthermore, they suggest developing a 'holding environment', where possible solutions are expressed and ideas are discussed in a safe environment. Within this space, leaders manage productive dialogue, ensuring that when conflicts arise, the discussions lead to constructive solutions. It is beyond the scope of this paper to examine all of the tips and tools suggested, but the approach is practical enough for leaders to understand the process.

Because adaptive leadership was developed for use by leaders in the field, the conceptual underpinnings of the model need further research and development (Northouse, 2016). The relationality of the different elements needs to be refined, including better describing some of the more abstract elements. An additional critique is that the strategies are too wide-ranging and sometimes too abstract; this plethora of helpful tools and tips could lead to confusion (Northouse, 2016). Perhaps by trying to be a model that could apply to the complex realities of many types of contemporary organizations, too many elements were introduced. Further articulation of the model may resolve this issue.

Although Heifetz introduced this model over two decades ago, there has been limited adoption of the model across different types of large organizations (Northouse, 2016). Each 
organization has unique structures and challenges, and as noted earlier in the paper, the evolving complexities of current organizations require different problem solving approaches. However, to date, there exists very little empirical research demonstrating the effective implementation of this leadership process (Dugan, 2017; Northouse, 2016). The assumptions and ideas upon which this model is built need to be further evaluated. A body of evidence generated by research would be beneficial not only for validating the theory but also for promoting further adoption of the model across large organizations.

This body of research could possibly address the critiques of the theory as outlined by Dugan (2017). Dugan agreed that there is not enough empirical research on the adaptive leadership model. More problematic, according to Dugan is the commodification of workers. Dugan (2017) described commodification as "the extent to which workers are considered fully agentic, vested partners in the process of production or simply tools to augment it" (p. 141). Dugan contended that the theory further reinforces the power dynamics of the organization, and can lead to workers becoming dependent on the direction of the leader or reacting to the leader's agenda, rather than working collaboratively to explore issues. Furthermore, the theory supports conflict and disequilibrium, but that kind of environment needs to be safe. Resistors to the process may be penalized socially or economically for their viewpoints, even though the theory identifies the idea of a holding environment to explore issues safely. The question of whether the process is guided by manipulation to achieve predetermined goals of the leader or by authentic efforts at collaboration to resolve complex issues needs to be resolved.

\section{Conclusion}

There is no disputing that the adaptive leadership process "is uncomfortable, as it challenges our most deeply held beliefs and suggests that deeply held values are losing relevance, bringing to the surface legitimate but competing perspectives or commitments" (Australian Public Service Commission, 2011, p. 14). As pointed out by Heifetz and Linsky (2004), it is important that educational leaders at all levels exercise adaptive leadership to allow those perspectives to come to the fore. The multiple and sometimes competing viewpoints and ideas are required to examine complex issues from new angles.

Moving away from the adjectival descriptors, behaviours, and situational contexts within which leaders have to operate, adaptive leadership provides an alternative approach that focuses on diagnosing the complex issues and collaboratively exploring the technical and adaptive elements embedded in the problems in order to construct an appropriate response. The adaptive leadership framework offers a unique means by which to conceptualize and sustainably address the unique challenges facing educational institutions today. 


\section{References}

Austin, I., \& Jones, G. A. (2016). Governance of higher education: Global perspectives, theories and practices. New York: Routledge.

Australian Public Service Commission. (2011). Thinking about leadership a brief history of leadership thought. Retriveied from Australian Public Service Commission website: http://www.apsc.gov.au/publications-and-media/current-publications/thinking-aboutleadership-a-brief-history-of-leadership-thought

Blake, R. R., \& Mouton, J. S. (1985). The managerial grid III. Houston, TX: Gulf Publishing Company.

Blanchard, K. H., Zigarmi, D., \& Zigarmi, P. (2013). Leadership and the One Minute Manager: Increasing effectiveness through situational leadership. New York: William Morrow.

Burns, J. M. (1978). Leadership. New York: Harper \& Row.

Chance, P. L. (2009). Introduction to educational leadership and organizational behaviour: Theory into practice.(2nd ed.). Larchmont, NY: Eye on Education.

Cronin, T. E. (1984). Thinking and learning about leadership. Presidential Studies Quarterly, 14 (1), 22-34. Retrieved from http://www.jstor.org/stable/27550029

Day, D., \& Antonakis, J. (2012). The nature of leadership. SAGE Publications. Retrieved from:https://serval.unil.ch/resource/serval:BIB_E24FFBFEBE58.P001/REF

Dinham, S. (2005). Principal leadership for outstanding educational outcomes. Journal of Educational Adminsitration, 43(4), 338-356. DOI: 10.1108/09578230510605405

Dugan, J. P. (2017). Leadership theory: Cultivating critical perspectives. Hoboken, NJ: John Wiley \& Sons.

Evers, C, \& Lakomski, G. (2013). Methodological individualism, educational adminsitration and leadership . Journal of Educational Adminsitration and History, 45(2), 159-173. DOI: $10.1080 / 00220620.2013 .768969$

Gardner, J. (1990). The nature of leadership. In The Jossey-Bass Reader on Educational Leadership (pp. 17-26). San Francisco: Jossey-Bass.

Heifetz, R. A. (1994). Leadership without easy answers. Cambridge, MA: Belknap Press.

Heifetz, R. A., Grashow, A., \& Linsky, M. (2009). The practice of adaptive leadership:Tools and tactics for changing your organization and the world. Boston, MA: Harvard Business Press. 
Heifetz, R., Kania, J., \& Kramer., M. (2004). Leading boldly. Stanford Social Innovation Review, 21 - 31. Retrieved from: http://ssireview.com

Heifetz, R. A.., \& Laurie, D. (2011). The work of leadership. In HBR's 10 Must Reads: On Leadership, (pp. 57-78). Retrieved from: http://thequalitycoach.com/wpcontent/uploads/2013/05/hbr-10-must-reads-on-leadership-1.pdf

Heifetz, R., \& Linsky, M. (2004). When leadership spells danger. Educational Leadership; 61 (7), $33-37$.

Hersey, P., \& Blanchard, K. H. (1969). Life-cycle theory of leadership. Training and Development Journal, 23, 26-34.

Ingleton, T. (2013). College student leadership development: Transformational leadership as a theoretical foundation. International Journal of Academic Research in Business and Social Sciences, 3, 219 - 229. DOI: 10.6007/IJARBSS/v3-i7/28

Katz, R. L. (1955). Skills of an effective administrator. Harvard Business Review, 33(1), 33 - 42.

Kelley, C., \& Peterson, K. (2002). The work of principals and their preparation: Addressing critical needs for the twenty-first century. In The Jossey-Bass Reader on Educational Leadership (pp. 351-401). San Francisco: Jossey-Bass.

Leithwood, K. (2007). What we know about educational leadership. In C. F. Webber, J. Burger, \& P. Klinck, P. (Eds), Intelligent leadership: Constructs for thinking education leaders, 6, 41-66. Springer Science \& Business Media.

Leithwood K., Jantzi D., \& Steinbach, R. (1999). Changing leadership for changing times. Suffolk: Open University Press.

McGregor, D. (1960). The human side of enterprise. New York: McGraw Hill.

Mumford, M. D., Zaccaro, S. J., Harding, F. D., Jacobs, T. O., \& Fleishman, E. A. (2000). Leadership skills for a changing world: Solving complex social problems. The Leadership Quarterly, 11(1), 11-35.

Northouse, P. (2013). Leadership: Theory and practice $\left(6^{\text {th }}\right.$ ed). Thousand Oaks, CA: Sage Publications.

Northouse, P. (2016). Leadership: Theory and practice $\left(7^{\text {th }} \mathrm{ed}\right)$. Thousand Oaks, CA: Sage Publications.

Owens, R. G., \& Valesky, T. C. (2014). Organizational behavior in education: Leadership and school reform (11th ed.). Boston, MA: Pearson. 
Paul, R. H. (2015). Leadership under fire: the challenging role of the Canadian university president. McGill-Queen's Press-MQUP.

Randall, L., \& Coakley, L. (2007). Applying adaptive leadership to successful change initiatives in academia. Leadership \& Organization Development Journal. 28(4), pp. 325-335. Doi.org/10.1108/01437730710752201

Riley, K., \& Macbeath, J. (2002). Leadership in diverse contexts and cultures. In

K. Leithwood, \& P. Hallinger, (Eds.), Second International Handbook of Educational Leadership and Administration, (pp. 351-358). Kluwer, Netherlands: Springer.

Robertson, J. M., \& Webber, C. F. (2002). Boundary-breaking leadership: A must for tomorrow's learning communities. In K. Leithwood, \& P. Hallinger (Eds.), Second International Handbook of Educational Leadership and Administration (pp. 519-553). Kluwer, Netherlands: Springer.

Spillane, J. (2005). Distributed leadership. The Educatonal Forum, 69 (2), 143-150. DOI: $10.1080 / 00131720508984678$

Stogdill, R. (1948). Personal factors associated with leadershiop:A survey of the literature. The Journal of Psychology, 25(1), 35-71.

Trachtenberg, S. J., Kauvar, G. B., \& Bogue, E. G. (2013). Presidencies derailed: Why university leaders fail and how to prevent it. Baltimore, ML: Johns Hopkins University Press.

\section{Author Biographies}

Tenneisha Nelson is a Doctoral Candidate in the Department of Educational Administration, College of Education, University of Saskatchewan. Her areas of research are leadership theory, school leadership and the principalship, as well as rural education.

Vicki Squires, $\mathrm{PhD}$, is an Assistant Professor, Department of Educational Administration, College of Education, University of Saskatchewan. Her areas of research are post-secondary education and student well-being, including an examination of how all stakeholder groups can achieve their goals while working together to achieve the mission of the university. 